\title{
Dermoscopy's contribution for the diagnosis of folliculotropic mycosis fungoides.
}

Gustavo Moreira Amorim 1,2,3*, Ingrid Reuwsaat Paul ${ }^{1}$, Bruna Molozzi ${ }^{1}$,

Elisa Rohsig Dannebrock ${ }^{1,4}$, Timotio Volnei Dorn ${ }^{1}$, Roberto Moreira Amorim Filho ${ }^{1}$.

${ }^{1}$ Sector of Dermatology. Santa Teresa Hospital. Santa Catarina State Secretary for Health.

${ }^{2}$ Faculty of Medicine. Universidade do Sul de Santa Catarina.

${ }^{3}$ Anatomical Pathology Post Graduation Program. Faculty of Medicine. Federal University of Rio de Janeiro.

${ }^{4}$ Sector of Dermatology. Polydoro Ernani de São Thiago University Hospital. Santa Catarina Federal University.

*Corresponding Author: Gustavo Moreira Amorim. 135 Duarte Schutel Street, ap 402, Downtown, Florianópolis, Santa Catarina, Brazil.

Received date: April 29, 2021; Accepted date: May 06, 2021; Published date: May 08, 2021

Citation: Gustavo M Amorim, Ingrid R Paul, B Molozzi, Elisa R Dannebrock1, Timotio V Dorn, Roberto Moreira A Filho. (2020) Dermoscopy’s contribution for the diagnosis of folliculotropic mycosis fungoides. Journal of Dermatology and Dermatitis.6(1); Doi: 10.31579/2578-8949/071

Copyright: (02021 Gustavo Moreira Amorim, This is an open-access article distributed under the terms of The Creative Commons. Attribution License, which permits unrestricted use, distribution, and reproduction in any medium, provided the original author and source are credited.

\begin{abstract}
:
Folliculotropic mycosis fungoides (FMF) is one of the three recognized variants of mycosis fungoides. FMF predominates in men over 50 years old. Often it takes a long time for the definitive diagnosis after the onset of skin lesions. Dermoscopy today represents almost an extension of the clinical dermatological examination, with its application being expanded day after day in medical literature. The authors demonstrate the dermoscopic findings recently described in the context of FMF (follicular accentuation / white halo around the follicles), in a case of typical clinical presentation, with a diagnosis confirmed by the clinical-dermatological correlation.
\end{abstract}

Keywords: Mycosis fungoides; dermoscopy; cutaneous T-cell lymphoma; cutaneous neoplasms

\section{Case report:}

80-year-old male patient, farmer, born and raised in Antônio Carlos (rural area), with systemic arterial hypertension, with a previous history of ischemic stroke, with motor sequelae in the right hemibody; was referred for evaluation of a skin lesion on the face. He referred its appearance at least 2 years ago, with progression in size and number of lesions slowly and progressively. He complained of itching associated with the lesions.

Upon examination, 3 lesions were identified. The one of greatest importance and clinical expression was found in the right supraorbital region. It was an infiltrated erythematous plaque, with well-defined edges, showing a follicular accent. Especially when compared to the contralateral eyebrow, it showed hair loss associated. In parallel, there was two erythematous nodules in the malar region, ipsilateral to the supraorbital lesion.
Dermoscopy revealed multiple yellow spots and white perifollicular halos, on a pinkish orange background with fine telangiectasias.

Histopathological examination of the lesional skin showed perifollicular lymphocytic infiltrate, predominating in isthmus and infundibulum, associated with folliculotropism. The presence of a discrete perivascular infiltrate and the presence of eosinophils were also observed. The interfollicular epidermis was preserved. Associated follicular mucinosis was identified. Immunophenotyping by means of immunohistochemistry determined the positivity of mature $\mathrm{T}$ lymphocyte antigens in the cells that permeated the follicular epithelium.

Clinical, histopathological and immunohistochemical findings allowed the diagnosis of folliculotropic mycosis fungoides. 


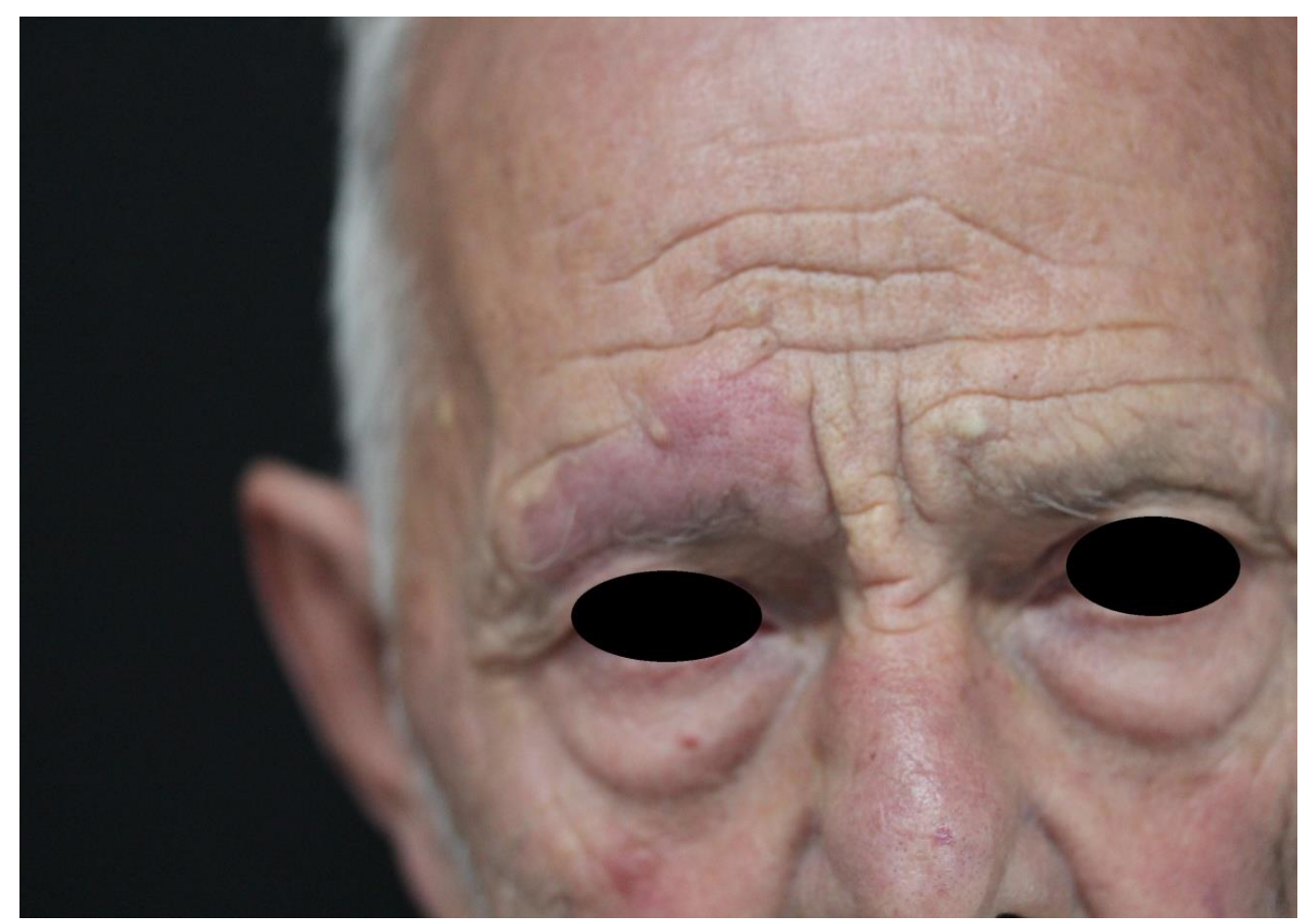

Figure 1: Pinkish, infiltrated, well-defined, erythematous plaque, affecting the supra-orbital region, causing a decrease in eyebrow hair.

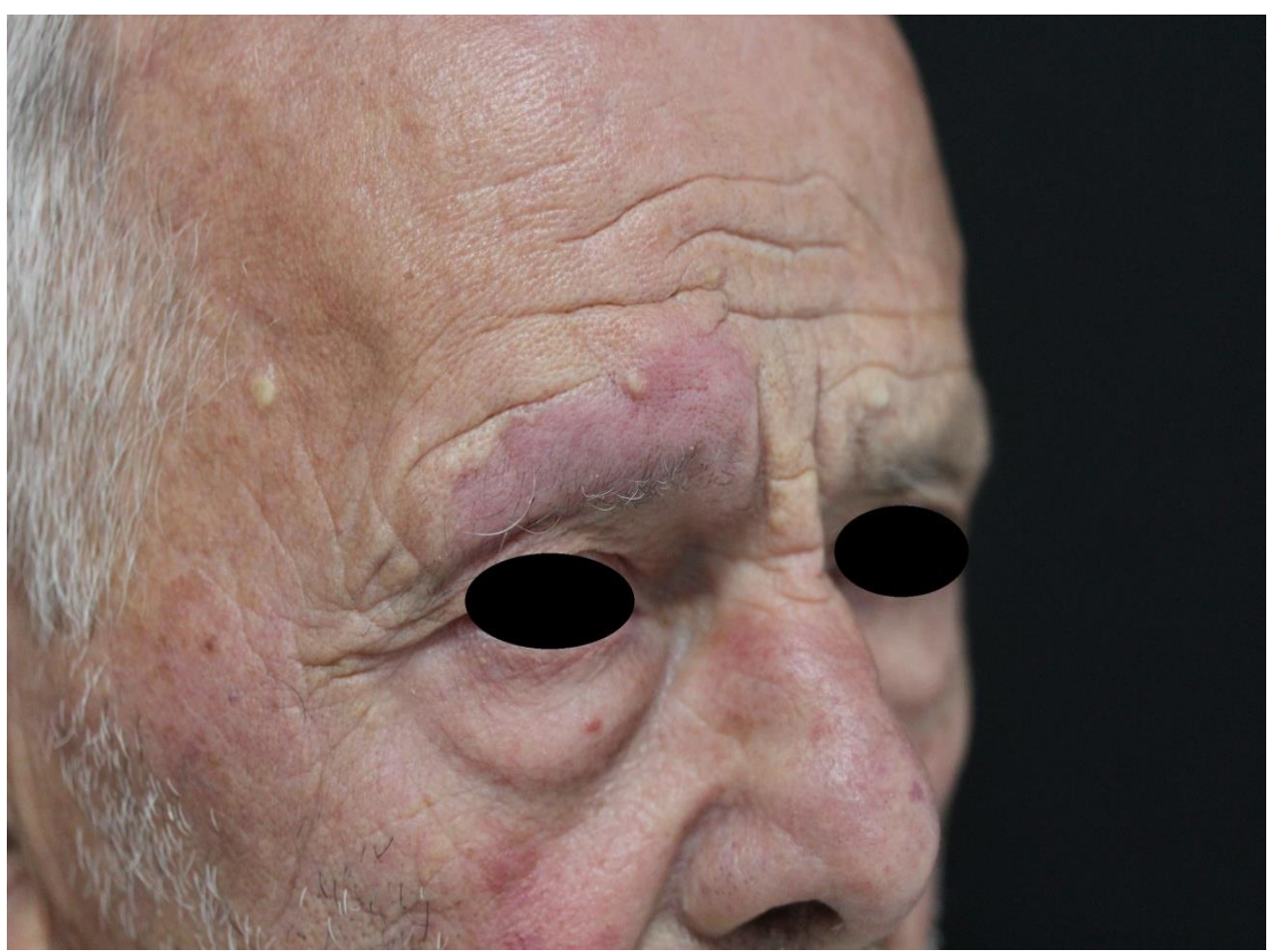

Figure 2: Pinkish, infiltrated, well-defined, erythematous plaque, affecting the supra-orbital region, causing a decrease in eyebrow hair. 


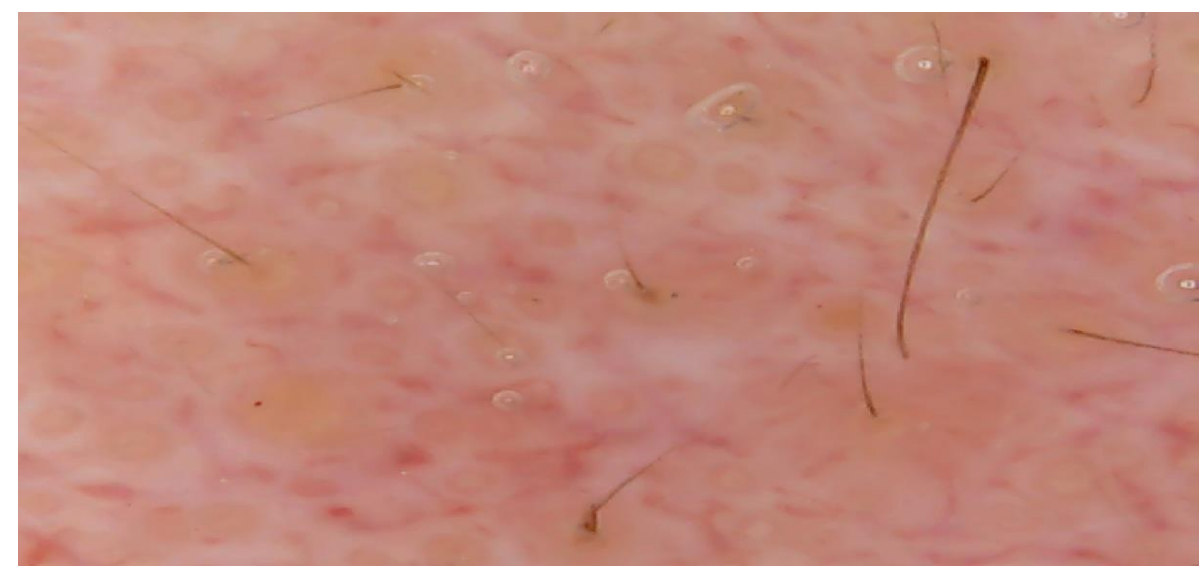

Figure 3: Decreased hair density; fine, short, linear vessels; orange-yellow patchy areas and perifollicular accentuation seen as a white halo around the follicles (Digital Dermoscopy; 40x; immersion with Alcohol-based gel).

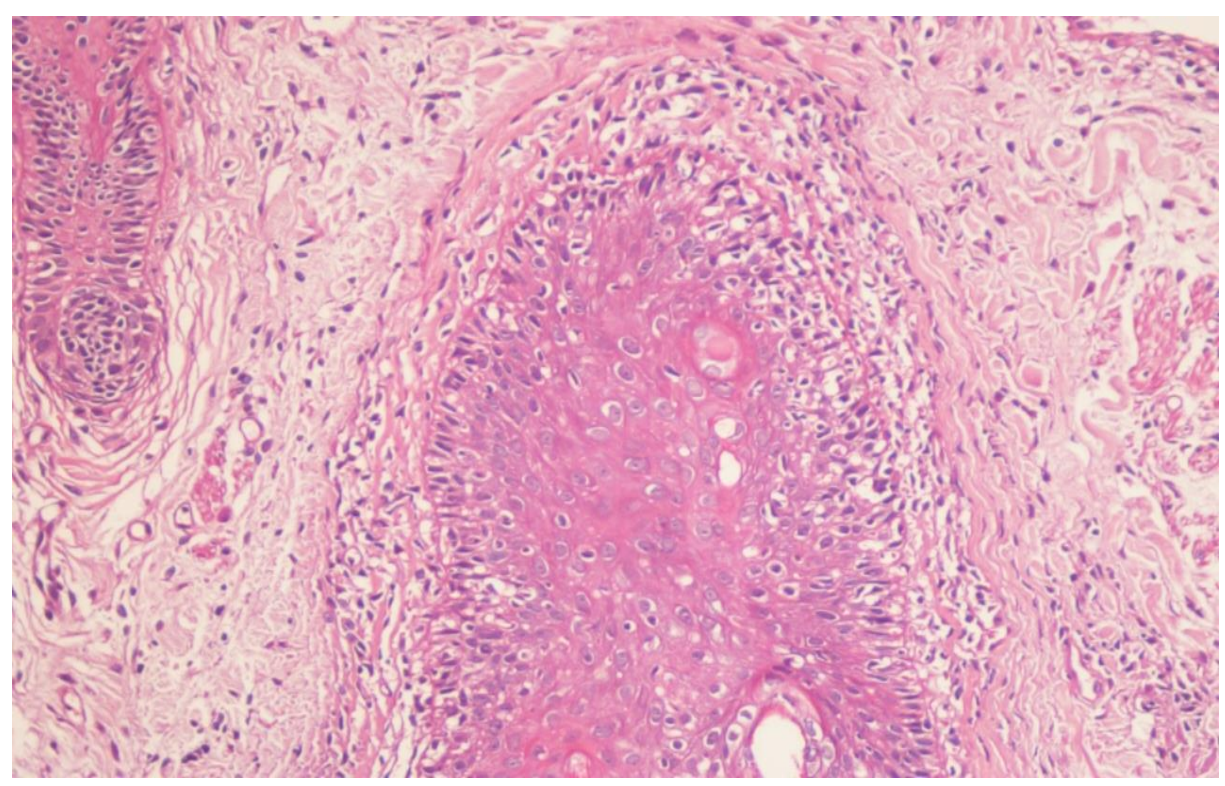

Figure 4: marked exocytosis of mononuclear cells surrounded by a clear halo in the follicular epithelium. OBJ 20x.H \& E.

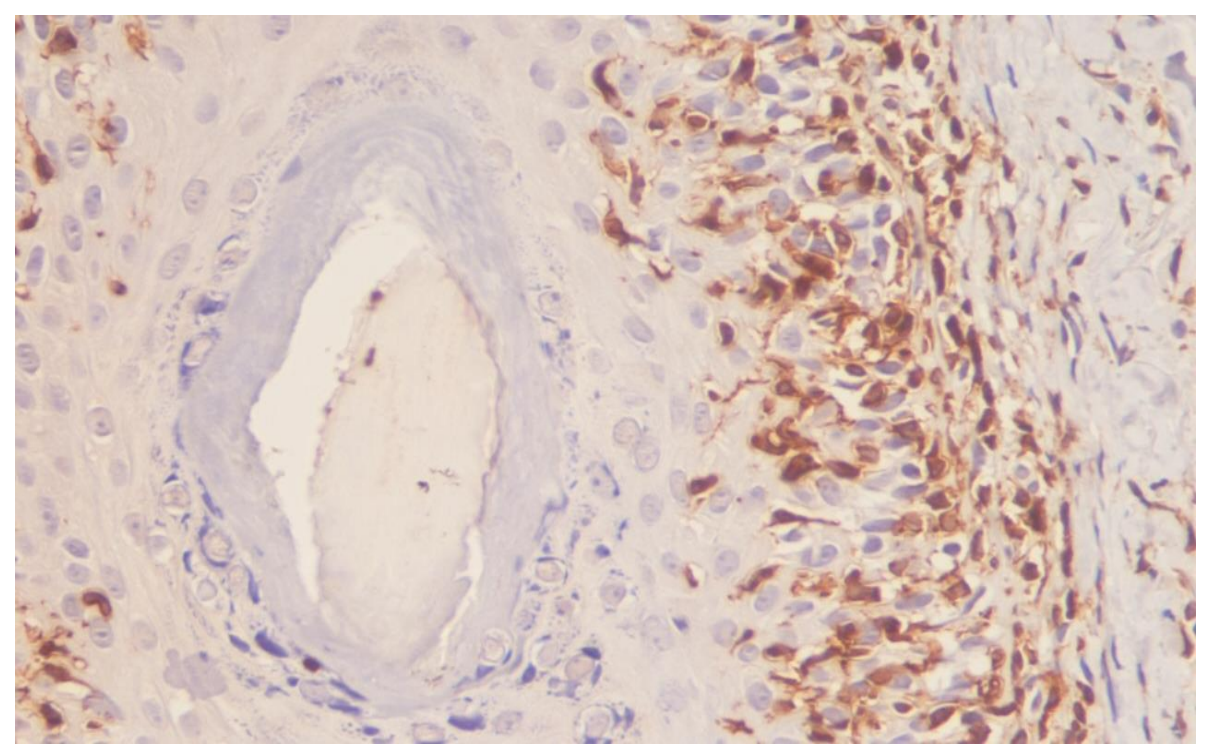

Figure 5: positive labeling for CD3 antigens on the lymphocytes that permeate the follicular epithelium. OBJ. 40x. CD3 immunohistochemistry. 


\section{Discussion:}

Mycosis fungoides (MF) is the most prevalent primary cutaneous T-cell lymphoma. Folliculotropic MF (FMF), according to the current classification of the World Health Organization (WHO) and the European Organization for Research and Treatment of Cancer (EORTC), is one of the three variants of classic MF (or Alibert-Bazin), along with pagetoid reticulosis and loose granulomatous skin [1-4].

FMF has as a fundamental aspect of its clinical-pathological definition: the marked presence of exocytosis of atypical $\mathrm{T}$ lymphocytes in the follicular epithelium (folliculotropism), associated or not with follicular mucinosis. Its first description is attributed to Giovannini et al., In 1906. This subtype of MF seems to be the most common among the "atypical", representing up to $12 \%$ of cases in some cohort studies. It predominates in men, from the 5 th decade of life [3-5].

The characteristic manifestations of classic MF are also the most common clinical findings associated with FMF - patches, plaques and tumors may occur. However, FMF presents with follicular accentuation, and plaques exhibit alopecia, comedones and erythematous follicular papules. Cysts and milia may also be found. Head and neck are the most frequently involved areas, and involvement of the eyebrows is highly characteristic. Pruritus is a common symptom that is often difficult to manage [4, 5].

The diagnosis of FMF is a challenge, given its polymorphic clinical presentation. The clinical-pathological correlation remains the "gold standard" for diagnosis. However, in general, the time between the onset of the condition and its definitive diagnosis is usually prolonged, averaging 24 months [6].

Dermoscopy is a non-invasive, low-cost and widely available method that allows visualization and characterization of colors, determination of vascular patterns and structures. It is incorporated into dermatological propaedeutics, making its use go beyond its initial objective in pigmented lesions. In addition, extensive literature supports its correlation with histopathological examination.

A pilot study seeking to characterize the dermoscopic findings of cutaneous lymphomas identified the presence of comedone-like structures in dilated follicular ostia (follicular pseudo-openings, classically described in seborrheic keratoses), surrounded by areas of peripheral stress [7]. Such an area of perifollicular accentuation, seen as a white halo around the follicles, would be a representation of the lymphoid infiltrate permeating the follicular epithelium, being an early finding of folliculotropism [8]. Its intensity is variable, according to the intensity of the lymphoid infiltrate and, sometimes, its visualization would be dependent on digital dermoscopy instruments [8]. As a tool for decision making, dermoscopy here would guide the biopsy exam, in order to surprise the finding of folliculotropism.

Possible findings in the context of FMF are described as the absence or reduction of terminal hair, an opaque or matte / copper red background, thin linear vessels and, less commonly, the spermatozoa-like vessels (similar to sperm) described in classical MF [7].

White areas without structure are a finding to be taken into consideration also in the evaluation of FMF, especially in more advanced lesions, since these would be the representation of fibrosis in topography of the follicular unit destroyed by the neoplastic process $[7,9,10]$.

We demonstrate the dermoscopic representation of a case of typical clinical presentation of FMF, confirmed by clinical-pathological correlation, seeking to reinforce the method as an extension of dermatological semiology, contributing to decision making and guiding a "better" histopathological sampling site, possibly shortening the time between symptom onset and definitive diagnosis. We emphasize that the literature on this subject is still scarce and based on small series of cases, and the validity of these criteria presented in prospective studies with a larger sample should be tested.

Data Confidentiality: The authors declare having followed the protocols in use at their working center regarding patients' data publication.

\section{Informed Consent: Obtained.}

Conflicts Of Interest: All authors report no conflict of interest.

Financial Support: No funding. Authors were responsible for the minimal costs involved in this article.

\section{Acknowledgements}

We are grateful for the contribution of dermatopathologist Gabriella Di Giunta Funchal, PhD.

\section{References}

1. Sanches Jr JA, Moricz CZM, Neto CF. (2006) Processos linfoproliferativos da pele. Parte 2 - Linfomas cutâneos de células T e de células NK. An Bras Dermatol.81(1):7-25.

2. Yamashita T, Abbade LP, Marques ME, Marques SA. (2012) Mycosis fungoides and Sézary syndrome: clinical, histopathological and immunohistochemical review and update. An Bras Dermatol.87:817-28.

3. Olsen E, Vonderheid E, Pimpinelli N, Willemze R, Kim Y, Knobler R, et al. (2007) Revisions to the staging and classification of mycosis fungoides and Sezary syndrome: a proposal of the International Society for Cutaneous Lymphomas (ICSL) and the cutaneous lymphoma task force of the European Organization of Research and Treatment of Cancer (EORTC). Blood. 110:171322.

4. Hodak E, Amitay-Laish I. (2019) Mycosis fungoides: A great imitator: Clin Dermatol. 37(3): 255-67.

5. Mittledorf C, Stadler R, Sander CA, Kempf W. (2018) Folliculotropic mycosis fungoides. J Dtsch Dermatol Ges. 16(5): 543-57.

6. Van Santen S, Roach REJ, van Doorn R, Horváth B, Bruijn MS, Sanders CJG, et al. (2016) Clinical staging and prognostic factors in folliculotropic mycosis fungoides. JAMA Dermatol. 152(9): 992-1000.

7. Ghahramani GK, Goetz KE, Liu V. (2018) Dermoscopic characterization of cutaneous lymphomas: a pilot survey. Int J Dermatol. 57(3): 339-43.

8. Toncic RJ, Drvar DL, Bradamante M, Rados J, Jerkovic-Gulin S, Caccavale S, et al. (2018) Early dermoscopic sign of folliculotropism in patients with mycosis fungoides. Dermatol Pract Concept. 31(8): 328-29.

9. Slawinska M, Sobjanek M, Olszewska B, Nowicki R, SkolowskaWojdylo M. (2018) Trichoscopic spectrum of folliculotropic mycosis fungoides. J Eur Acad Dermatol Venereol. 32(3): e107e108.

10. Caccavale S, Vitiello P, Franco R, Panarese I, Ronchi A, Sica A, et al. (2019) Dermoscopic characterization of folliculotropic mycosis fungoides selectively localized on trunk and limbs. Int $\mathbf{J}$ Dermatol. 58(10): e187-e189. 